\title{
Erratum to: Age-related delay in urinary stone clearance in elderly patients with solitary proximal ureteral calculi treated by extracorporeal shock wave lithotripsy
}

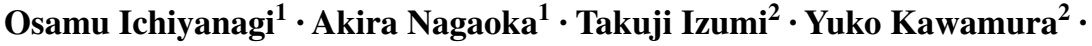 \\ Tomoyuki Kato ${ }^{1}$
}

Published online: 11 November 2015

(C) Springer-Verlag Berlin Heidelberg 2015

\section{Erratum to: Urolithiasis (2015) 43:419-426 \\ DOI 10.1007/s00240-015-0783-3}

Unfortunately, original version of this article has been published with incorrect $p$ value in Fig. 4. The correct $p$ value is 0.064 . The revised figure is placed in the following page.

The online version of the original article can be found under doi:10.1007/s00240-015-0783-3.

Osamu Ichiyanagi

o.ichiyanagi@med.id.yamagata-u.ac.jp

1 Department of Urology, Yamagata University Faculty of Medicine, Iida-Nishi 2-2-2, Yamagata City, Yamagata Prefecture, Japan

2 Department of Urology, South Miyagi Medical Center, Aza-nishi 38-1, Ogawara Town, Miyagi Prefecture, Japan 


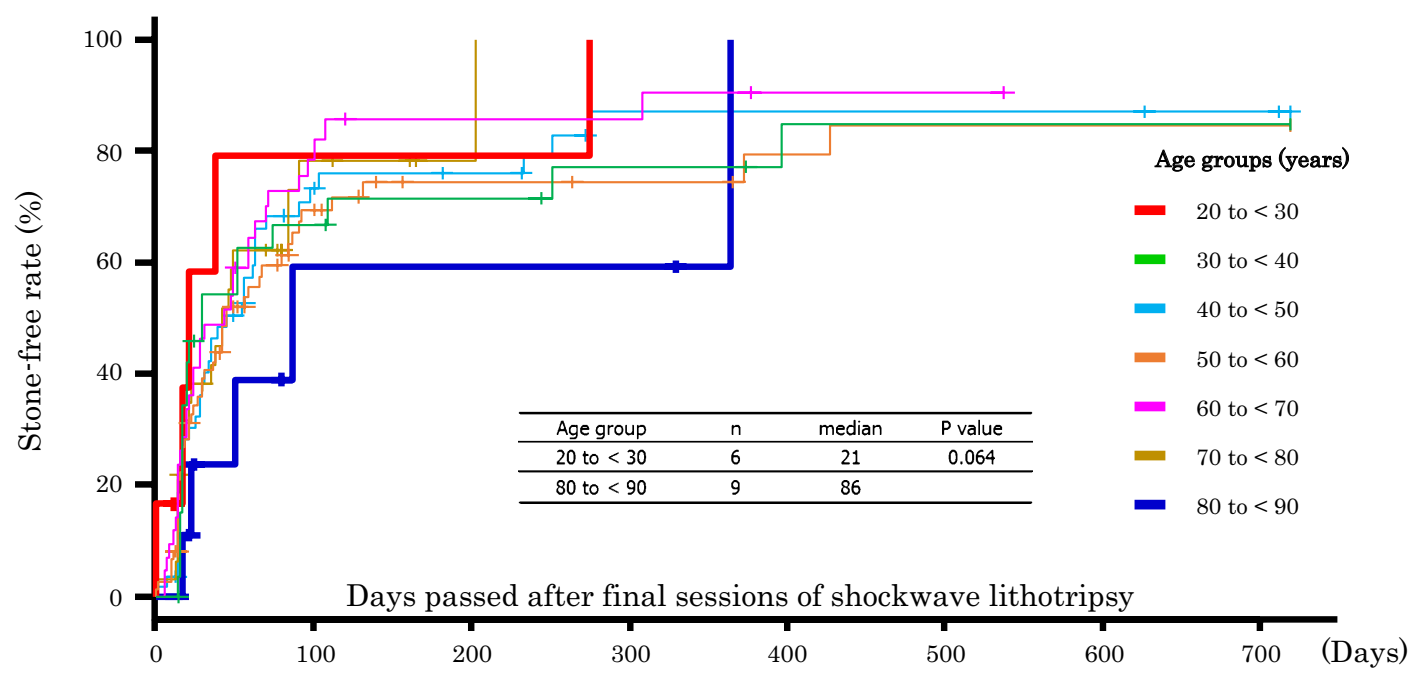

\begin{tabular}{lcccccccc} 
Age group & Number at risk & & & & \\
\hline 20 to $<30$ & 6 & 1 & 1 & 0 & 0 & 0 & 0 \\
\hline 30 to $<40$ & 30 & 8 & 6 & 4 & 2 & 3 & 2 \\
\hline 40 to $<50$ & 54 & 11 & 8 & 3 & 3 & 3 & 3 \\
\hline 50 to $<60$ & 74 & 11 & 8 & 3 & 3 & 1 & 1 & 0 \\
\hline 60 to $<70$ & 42 & 6 & 4 & 1 & 0 & 0 & 0 & 0 \\
\hline 70 to $<80$ & 32 & 2 & 2 & 2 & 0 & 0 & 0 \\
\hline 80 to $<90$ & 9 & & & & & 0 & 0
\end{tabular}

Fig. 4 Kaplan-Meyer analysis of the duration from the final shock wave lithotripsy (SWL) session to stone passage for the different study groups. Although the estimated values of $50 \%$ stone-free rate (SFR) for patients aged 20 to $<30$ and 80 to $<90$ years were not sig- nificantly different, the difference seemed so great that it suggested the tendency of elderly patients to pass solitary proximal ureteral stones treated by SWL later than younger patients ( 21 vs. 86 days for patients aged 20 to $<30$ vs. 80 to $<90$ years; $p=0.064$, log-rank test) 